UDC 811.111

DOI: $10.17223 / 24109266 / 6 / 2$

\title{
EROTIZATION AS THE BASIS OF FEMALE METAPHOR IN THE ENGLISH LANGUAGE
}

\author{
L.P. Murashova ${ }^{1}$, L.V. Pravikova ${ }^{2}$ \\ ${ }^{1}$ Southern Institute of Management (Krasnodar, Russian Federation). \\ ${ }^{2}$ Pyatigorsk State Linguistic University (Pyatigorsk, Russian Federation). \\ E-mail: L-P-Murashova@mail.ru; pravikova@mail.com
}

\begin{abstract}
The article presents a logical-semantic analysis of metaphors, encoding women in English from the erotic standpoint. In the erotic metaphor a female image is revealed in a binary division: the woman as a passive object that is to meet the needs of men, and as an active agent, when she lures men, manipulates them, cheats, uses them to her own advantage, that is, her sexual behavior is in opposition to the ideas of stereotypical hierarchical patriarchal structure and phallocentricity of the universe. Important areas of erotic feminine metaphors refer to coding the semantics of women of easy virtue and lesbians. The analysis has shown that representativeness and semantic density of these metaphors are high enough and they are cognitively foregrounded in the English language and mind. The metaphoric projections of women move from bodily sensations (with the emergent scheme) to mental, epistemic or logical domains.
\end{abstract}

Keywords: erotic metaphor; gender; culture; society; the English language.

\section{Introduction}

Speaking of metaphors in connection with the representation of the female worldview, we can agree with B. Fraser, that metaphors are "black holes in the universe of language" and that they are often used as a means of disguising sexual information [1: 339-340]. As a scientific term the "black hole" refers to a hypothetical body in space, to an invisible collapsed star that has shrunk so much that nothing can escape its gravitational field, but in a broader sense, the term is also frequently used by machos to besmirch women as empty-headed or all devouring monsters [2].

Sex is a division of species to masculine or feminine, in particular in relation to the reproductive function [3-8]. The word sex in English was first noted in the 1350-1400. It was formed from the Latin word sexus, probably from the same root as secāre "divide" (compare with Russian. "sech" - to cut to pieces) and was used in relation to two main categories of mankind - men and women. At the end of the 14th century the word sex meant "males or females collectively". The lexeme sex began to be used not only to refer to the separation of sexes, but to indicate qualities of being male or female. The meaning "quality of being male or female" was first recorded in the 1520s. The meaning "sexual intercourse" appeared in 1529 (in the works of 
D.H. Lawrence), sex object - 1901 sex appeal - in 1904, sex drive - in 1918; sex symbol - in anthropology in 1871; first person to whom the latter term has been applied, was apparently Marilyn Monroe (1959) [3]. Speaking about men in general, people used such expressions as the better sex, the sterner sex, which stress positive characteristics of men, for example, strength. Women, on the contrary, are described as the weaker sex: fair sex, gentle sex, as the sex that has a secondary position in relation to a man: the second sex, contrary sex.

\section{Methods and procedures}

Metaphorical constructions are the part of culture and are rooted in society and discourse. Roland Barthes in Le Plaisir du Texte [4] states that "the text has human form" that it is "an anagram" of our "erotic bodies". The metaphor "woman as a text" has been often cultivated by metaphysical poets.

Objectivation of feminine essence in metaphor is based on patriarchal practices and is often associated with sexual or erotic characteristics of a woman's identity and her behavior. Simone de Beauvoir in her book "The Second Sex" ("Le deuxième sexe") first made a statement that woman is defined as "the other one", she is an object in relation to the male subject and thus - the object of marginalization [5].

Women, according to the ideas of ancient Greeks, do not apply to the human race. They should obey men without question, they have to keep their virginity only for lawful wedded husband, to keep the family hearth and give birth only to sons [6-8].

Reification of women, nominative conceptual transformation of them from people into objects of consumption, the evaluation from the point of functionality, and in the latter case, the identification of women with regard to their bodies, leads to their dehumanization, depersonalization and sexual humiliation of their human dignity. For example, the word piece "woman" (in its primary meaning "bit", "part", "thing") implicitly indicates the deficiency and insufficiency of women relegates women to the level of things. The expression "Miss Thing" refers to a woman perceived only from the point of view of her role as a sexual partner, "warm body" positions woman as a sex object exclusively, the noun "maness", meaning woman (archaic.), shows the secondary position of a women in relation to men (man + -ess).

"Identity" is a central concept for many contemporary cultural, social and linguistic studies. The term "identity" is paradoxical in itself and means identity and originality, and this contradiction is increased in relation to the description of women. The notion of identity is the recognition that a person embodies a special combination of attributes and capabilities. These attributes and abilities influence the interaction of the individual with others, which in turn affects the identity of a person. Identity can be viewed at as the 
interpretation of person's experience and the world around him. It indicates multi-faceted nature of individual personal identification, experience and associations.

The woman is identified with creation and protection. She is described in terms of fertility / fecundity and reproduction; she is the mother, creating a man from her own material, and then supporting, defending and protecting him. In order to exist in society, women are forced to identify themselves with the images created for them by patriarchal ideology. These include, among others: the image of the mother, the Virgin, the femme fatale, the prostitute, all of whom are the subject of men's desire.

According to Freud's theory, sexual symbolism refers to many ordinary things, in particular, to flowers, fruits, different artifacts, etc. The list can be continued: to animals, food, objects of nature, etc.

Associations of women with flowers as metaphors of fertility are old and are used in many languages. Flowers are used as both positive and negative symbols of female sexuality. Instrumental and symbolic role of women are projected on "universal" values of motherhood and femininity in form of fetishised body parts of a woman. The association of woman with flower evokes a vision of a defenseless beautiful creature in need of protection.

Floristic terminology, bearing floral symbolism, often uses parallel analog correlation between flowers or their parts and aspects of female sexual anatomy, such as the bosom, womb, labia and vagina, and also nominates the stages of women's sexual and reproductive activity and sexual status and actions. If we extrapolate this symbolism further, mankind is born from the womb of a woman, which means that the sexual and reproductive organs of women are the "essence" or "flower" of humanity. Puberty, female physiological processes that happen in the body, first sexual experience, fertility, pregnancy and motherhood are conceptualized through floristic terms: enclosed buds, ripe blossoms. The lexeme "flowering" is sometimes used to describe a particular period for a woman - in the phrase "menstrual flowering".

"Rosebud" is a nomination of a beautiful blossoming young lady. The verb deflower is a euphemism for the name of the act of rupturing a hymen through sexual penetration. The internal form of the verb "to pluck the petals of a flower" correlates with the meaning of the transition from the state of a blossoming organism as an essence of an innocent girl to the loss of this essense and its transformation into a female flowering. The phrase "to cop a cherry" (to be the first one to have sex with, to $f *$ ck a virgin) means to be the first sexual partner of a virgin. The verb "to bloom" has the same root as "to blow".

The lack of female sexuality - innocence, chastity, virginity has secondary nomination through floral codes when concepts such as "rose", "lily", "enclosed garden" symbolize the ideal of feminine beauty and impregnability. 
The concept Garden serves as a metaphor both for the female body as a whole, and for the female sexual organ. Garden where fragrant herbs, fruits, flowers or trees grow, is a symbol of fertility, a symbol of place for enjoyment. The word garden has the same etymological meaning as "paradise" (see Persian. Pardec (paradeisos) "paradise"). The garden is a metaphor of sexual paradise (Song of Solomon 4: 12-16) [9]. A cloistered garden became a symbol of sexual integrity, virginity, impermeability to the outside world. A woman's body is perceived as an enclosed garden. Words "A garden enclosed is my sister..." relate to Shulamith's body. In verse 16 of the canticle of canticles, the word garden refers not only to the body of a woman in general, but also to her genitals in particular. The interpretation of the passage is clear: Shulamith metaphorically compares her female sexual organ to a garden. Eating sweet fruits of this garden symbolizes a metaphor for lovemaking. Eden Gardens in the biblical tradition are images of paradise lost and paradise regained.

The word flower is used as a euphemism for women selling their bodyes, and the phrase flower market for the nomination of prostitution. The expression flower smoke rooms means rooms in which customers could smoke opium and communicate with the ladies of the demimonde at the same time. And the patron, who paid dearly for the privilege of "defloration" of a girl that had been introduced to the profession for the first time arranges a feast for his friends in a brothel to celebrate a procedure known as celebrating the flower "a celebration of the flower" [10].

Food in conceptual metaphor often has euphemistical meaning of exploitative sexual attitude towards women: dish, seafood, tart, cookie, cheesecake, tuna, etc. Food and its consumption are symbolically associated with sex. Associative figurative parallels stimulate the creation of gender-specific metaphors. Body language is translated into the language of hunger, desire and lust. A Source domain "Sweets" creates metaphorical expressions, in which woman is conceptualized indirectly as an erotic object, an object of sexual and aesthetic admiration and desire to possess: honey, angelcake, bit of jam, peach, and other.

Anatomy and physiology of sex. Women and female organs are seen as edible objects for male consumption. For example, the female reproductive organs are represented in English by the names of vegetables: artichoke, cabbage (garden); meat: beefbox, bit of pork; dessert: basket of goodies, bit of jam, cake, etc.

A part of a woman's body - breasts as a special manifestation of femininity is an attractive sexual object. It symbolizes femininity, motherhood, fertility, prosperity, and it is also a sexual weapon. Metaphorically, in English slang, they have many names, only $2 \%$ of which neutrally describe female biology, while others are rude nicknames or sexual names. Priority is given to the nomination based on visual similarity with some fruits and vege- 
tables of rounded shape and of pleasant taste and / or pleasant to touch: apples, melons, cantaloupes, cherries, bell peppers, chestnuts, coconuts; with sweets and candies: bonbons, basket of goodies, cakes, cherry-topped sundaes, raspberry tart, cupcakes; with milk containers and products: dairies, cream jugs, milk cans, milk wagons, baby's dinners; with meat products: bangers, animals: piggies, weapons: barbettes; bazookas, with a device for knocking at the door: knockers; musical instrument: maracas; et al. (see. [11]).

The domain "animals" is one of the most productive for depicting sexual aspects of a woman metaphorically. Human beings are most often understood in terms of the (alleged) properties of animals [12: 19]. Thus, metaphors formed from the names of pets: kitten, pussy, young pets: filly, birds: chick, dove, nightingale, beetles and butterflies: beetle, butterfly, bear sexual connotations. The performance of femininity - weakness, small size, youth - stresses the masculinity of the stronger sex, make it possible to create the illusion of love - ladies do not always sell sex, and often give affection and love. Some metaphorical names may carry both positive and negative connotations applied to women: bird, pigeon, pussy, fox, vamp.

The roles of women are different - a passive object, a giver, a destroyer and creatress.

Musical instruments symbolize potential of a person physically and socially express his needs, desires, passions and creative forces in the harmony of sounds. Musical instruments are important cultural artifacts that bear a wide meaning and have a certain power resources. Their presence, the sounds they produce, images that they evoke, make it possible to change cognitive states and tuning of recipients, ie to transform consciousness. The meanings of musical instruments are encoded in their forms, their use, their purpose. Visual metaphor is often based on visual images. For example, a woman's body is a violin, her breasts are maracas - a South American percussion instrument of precussion type, kind of a rattle. Conceptually, music is understood as a metaphor of emotions, thoughts, perpetual motion, life and beauty. Gender meanings are built in the framework of relationships between a human and musical instruments.

Gender meaning can be applied to any artifact. The meanings of physical objects are derived from the relationship between objects and people. They can serve as markers of asymmetric evaluation of the functioning of women and men in the genital area from the point of stereotypes that exist in society. For example, a man thinks that a woman behaves reprehensibly, if she has casual sexual affairs. In this case, it is acceptable to call the female a slut. According to the logic of men, women are associated with a lock, and men - with a key. If a key opens a lot of locks it's a good key but if a lock opens up to a lot of keys then it's a shitty lock [13]. This metaphorical nomination of a woman shows that woman has no value on her own, and is a complex device, a mechanical problem that must be solved. At the same 
time, to solve the problem is the task of a man, who is believed to have the necessary physical and physiological resources. These associations reinforce outdated sexual double standard that is rooted in archaic notions of masculinity and female chastity.

In the erotic metaphor female image is revealed in binary splitting. On the one hand, the woman is shown as a passive object that exists to meet the needs of men, on the other, the woman represents an active source: she evokes certain emotions in men, lure them, manipulate them, mystifies, deceives, uses them for her own purposes.

From the active plans as a deconstructive being a vampire, monster, dangerous opponent in sexual battles: vampire, monster, houri; as a domineering agent: virago, dragoness. Sexual influence and power of a woman are conceptualized in metaphors witch, sorceress, enchantress, sibyl, wise woman, charmer, beldam, hex, femme-fatale, in which woman is presented as a sorceress and a witch who lures a man into her arms. She is a seductress, a ruthless hunter, who draws a man into sex using her beauty, various tricks, traps and direct violence, something smashing and awesome: temptress, Delilah, siren, beauty dish, knockout, looker, lulu, mantrap, peach, ravisher, smasher, stunner, sweetheart. Metaphors, in which woman actively displays her sexuality, are in opposition to the idea of stereotypical patriarchal hierarchical structure and phallocentrism of the universe in which a female desire is limited and historically has no right to exist. Negative connotations are connected with amazons, mythical women in whose world men have a small role of impregnation, and then are subjected to utilization. These are woman, wanton and impetuous, who pose a threat to traditional marriage. Their behavior is masculine, because they are engaged in traditionally male activities - riding on horseback and military affairs.

One of the most important areas of gender feminine metaphor refers to the encoding of the meaniing of a women of easy virtue, who lives idecent life. Prostitute is a person, most often a woman who earns on paid sexual services, the one who lives partly or wholly on prostitution. The lexeme prostitute is derived from the Latin verb "prostituere", which means to expose publicly, to offer for sale by public exposure.

Metaphors nominating women with low standards of sexual purity are numerous in the English language. The following names mean women professionally engaged in sex on demand for money, ie representatives of the oldest profession, prostitutes. Features on which generalization is based are the following:

1) generalization of prostitution as work or activity of women: business girl, working girl, body worker, sporting girl;

2) external features: cock-eyed jenny, bob tail, painted woman, dirtyleg, lowheel, blue gown, bluefoot, flesh pot; 
3) functional professional prototypical actions and sexual techniques: call girl, cum-catcher, window tapper, vent renter, pintle-twister, ass peddler, butt-peddler, poker climber, foreskin hunter, hooker, merry-legs, flatbacker, needle-woman, speedy sister, fast-fanny, coffee grinder;

4) social value: mattress, hat-rack, hay-bag, hose-bag, garbage can, garbage woman, barrack hack, village bicycle;

5) place in the hierarchy: bottom woman;

6) insignificance: moth, cheap thing, dirty thing;

7) target purpose: sailor's bait, common sewer, piece, piece of trade, dress for sale, lease-piece, company girl, joy boy;

8) attendant temporal and local circumstances: woman about town; moonlighter; streetwalker, night jobber, camp follower, ammunition whore, nymph of darkness, alley cat, pavement princess, overnight bag, red-light sister, escort, lot lizard, apartment girl, fly-by-night;

9) ethical evaluation: vice sister, bad girl, bad woman;

10) ayment methods: coke whore, dope whore;

11) professionalism: amateur, etc.

Another use of feminine metaphors is the nomination of a gay woman [14]. Terminology for homosexual women often includes lexical units or complexes in which there are nominations, pointing to the opposite sex: male proper names: amy-john (late 1950s), derrick, jasper (NYC late 1960s); simple and complex nominations, that include the names of men: brothergirl; fellow; king; king stud; manflora; marimacho; she-male; she-man, masculine pronouns: he-she; as well as nominations with direct and indirect reference to the prototypical actions and moods of lesbians: girl kisser; ladylover; horsewoman; shesexual; penis-envy queen; names that describe the intensity of contacts: big diesel; big diesel dyke; external features of agents: pansy without a stem (mid 1960s), or their function: dyke; proximity type: collar-and-tie (1040s), and others.

\section{Conclusion}

Metaphor is the result of projecting, or displaying of conceptual scheme from one domain to another. Logical-semantic and cognitive-frame analysis of metaphors that conceptualize women, showed that these cognitive metaphors are highlighted in the consciousness of English language speakers. Their representativeness and semantic density are sufficiently high. They rely on comparisons and analogies between the real world objects and abstract concepts and fix both ontological aspects of figurative representation of women in general, and their gender-specific portraits from the point of view of men within the framewwork of the dominant - dependent asymmetric model of relations between the sexes. 
Reflection of the actual state of affairs in the world through metaphorical code identifies the particularities of ethno-national and gender language picture of the world, reveals particularities of etnospesific thinking within the system of values, shows the dependence of the verbalization of the world picture from the stereotypes in society. Metaphorical projections of women shift from bodily sensations (with emergent scheme) to the mental, epistemic or logical domains.

\section{References}

1. Fraser, B. (1993) The interpretation of novel metaphors. Metaphor and Thought. A. Ortony (ed.). New York: Cambridge University Press. pp. 329-341.

2. Mansbridge, P. (2000) Metaphor, Male / Female Theorists, and the "Birth Rites" of Women: The Reclamation Projects of Sylvia Plath, Anaïs Nin and Maya Deren: A Thesis Submitted to the Faculty of Graduate Studies in partial fulfillment of the Requirements for the Degree of Master of Arts. Ottawa. [Online]. Available at: http://mspace.lib.umanitoba.ca/bitstream/1993/2572/1/MQ59915.pdf.

3. Sex. Dictionary.com. [Online]. Available at: http://dictionary.reference.com/ browse/sex?s=ts

4. Barthes, R. (1973) Le Plaisir du texte. Paris: Le Seuil. 105 p.

5. Beauvoir de, S. (1949) Le deuxième sexe. Paris: Gallimard. 2 volumes.

6. Golosovker, Ya.E. (1993) Tales of the Titans. Moscow: Niva of Russia. $136 \mathrm{p}$.

7. Publius, V.M. (1971) Bucolic. Georgics. Aeneid. Moscow: Hudozhestvennaya literatura. $462 \mathrm{p}$.

8. Amazons. Encyclopedia of fictional creatures. [Online]. Available at: http://www.bestiary.us/blogs/dmitrij/amazonki.

9. Song of Solomon 4:12-16. [Online]. Available at: http://www.biblestudytools.com/nkjv/song-of-solomon/passage.aspx?q=song-of-solomon+4:12-16.

10. Frownfelter, A. (2010) Flower Symbolism as Female Sexual Metaphor. Senior Honors Theses. Ypsilanti: Eastern Michigan University Paper. 88 p.

11. 262 Names for Boobs. [Online]. Available at: http://mycampustalk.com/262-names-forboobs.

12. Kövecses, Z. (2010) Metaphor: A Practical Introduction. New York: Oxford University Press. $375 \mathrm{p}$.

13. On a disgusting metaphor. [Online]. Available at: http://dearcoquette.com/ post/1585403701/on-a-disgusting-metaphor.

14. A Brief Dictionary of Queer Slang and Culture. Submitted by Rebecca Scott. [Online]. Available at: http://www.oocities.org/westhollywood/stonewall/4219. 